\title{
Development of Analytical Method for Detection of Some Pharmaceuticals in Surface Water
}

\author{
Fouad Fadhil Al-Qaim ${ }^{1,2}$, Md Pauzi Abdullah ${ }^{1,3^{*}}$, Mohamed Rozali Othman ${ }^{1,3}$, \\ Jalifah Latip ${ }^{1}$ and Wan Mohamed Afiq ${ }^{1}$ \\ ${ }^{1}$ School of Chemical Sciences and Food Technology, Faculty of Science and Technology, Universiti Kebangsaan (UKM), 43600 \\ Bangi, Selangor. Malaysia, ${ }^{2}$ Chemistry Department, Faculty of Sciences for Women, Babylon University, PO Box 4, Hilla, Iraq, \\ ${ }^{3}$ Centre for Water Research and Analysis (ALIR), Faculty of Science and Technology, Universiti Kebangsaan (UKM), 43600 \\ Bangi, Selangor. Malaysia.
}

*For correspondence: Email: mpauzi@ukm.my; Tel: +060193295636

\begin{abstract}
Purpose: To develop and validate a simple method using solid - phase extraction along with liquid chromatography-time of flight mass spectrometry for the analysis of pharmaceuticals in surface water of Tangkas River, Malaysia.

Methods: Liquid chromatography (LC) was performed on a Dionex Ultimate 3000/LC 09115047 (USA) system equipped with a vacuum degasser, a quaternary pump, an autosampler and UV-Vis diod array detector. Chromatography was performed on a Thermo Scientific C18 (250 mm x $2.1 \mathrm{~mm}$, i.d.: $5 \mu \mathrm{m}$ ) column. The injection volume was $20 \mu \mathrm{L}$. All compounds (hydrochlorothiazide, gliclazide, diclofenac-Na and mefenamic acid) were analysed in negative ion (NI) mode and eluted off the column with a mobile phase consisting of (A) $0.1 \%$ formic acid (FA) in deionised water (DIW) and (B) $40 \%$ acetonitrile (ACN) in methanol $(\mathrm{MeOH})$ at $0.3 \mathrm{ml} / \mathrm{min}$. Mass spectrometry was performed on a time of flight (TOF) instrument.

Results: The linearity range, $5-500 \mathrm{ng} / \mathrm{mL}$, provided a determination coefficient $\left(R^{2}\right)>0.99$ for all compounds. The limit of detection (LOD) ranged from $65-136 \mathrm{ng} / \mathrm{L}$ while recovery ranged from 45 $111.2 \%$ in the river water. Two pharmaceutical compounds were detected in the surface water samples: diclofenac sodium and mefenamic acid at concentrations of 340 and $545 \mathrm{ng} / \mathrm{L}$, respectively.

Conclusion: The developed method is linear in the range $5-500 \mathrm{ng} / \mathrm{mL}$, and precise and acceptable recoveries were obtained. In addition, this method is suitable to identify and quantify trace concentrations of diclofenac sodium and mefenamic acid in surface water.
\end{abstract}

Keywords: Diclofenac, Mefenamic acid, Electrospray lonization, Mass spectrometry, Solid phase extraction (SPE), Tangkas river, Collision energy.

Tropical Journal of Pharmaceutical Research is indexed by Science Citation Index (SciSearch), Scopus, International Pharmaceutical Abstract, Chemical Abstracts, Embase, Index Copernicus, EBSCO, African Index Medicus, JournalSeek, Journal Citation Reports/Science Edition, Directory of Open Access Journals (DOAJ), African Journal Online, Bioline International, Open-J-Gate and Pharmacy Abstracts

\section{INTRODUCTION}

Pharmaceuticals are synthetic or natural chemicals that can be found in prescription medicines, over-the-counter therapeutic drugs and veterinary drugs. Pharmaceuticals contain active ingredients that have been designed to have pharmacological effects and confer significant benefits to society. The occurrence of pharmaceuticals in the environment and the water cycle at trace levels (in the range of nanograms to low micrograms per litre) has been widely discussed and published in the past decade [1-4]. Increased detection of pharmaceuticals in aquatic environment is largely 
attributable to the advances in analytical techniques and instrumentation.

Trace concentrations of pharmaceuticals in the water cycle have raised concerns over potential human health risks from exposure to very low levels of pharmaceuticals in drinking water. Of the pharmaceuticals reported in the literature, diclofenac and mefenamic acid (non-steroidal acidic anti-inflammatory drugs (NSAIDs)) are the most frequently mentioned as environmental pollutants [5-10].

Determination of pharmaceuticals can be performed by various techniques, icluding highperformance liquid chromatography (HPLC) [11, 12] and gas chromatography-mass spectrometry (GC-MS) [13,14]. HPLC is the most common method used for separation and determination of these compounds because most pharmaceuticals are non-volatile. The analysis of drugs in a complex matrix such as surface water without sample preparation is very difficult. In general, sample preparation and concentration of the target analytes are often needed before analysis. Up to now, several procedures have been developed for preconcentration of pharmaceuticals from sample matrices including liquid-liquid extraction (LLE) [15] and solid-phase extraction (SPE) [16].

SPE offers unquestionable advantages over the traditional LLE technique, including greater extraction efficiency and lower consumption of organic solvents. Solid-phase microextration (SPME) [17], and liquid-phase micro-extraction [18] have been also applied for extraction of pharmaceuticals. Occurrence of human pharmaceutical pollutants in Malaysian environment has never been studied before except for Langat River [3]. This study is therefore aimed at investigating some pharmaceutical contaminants in Tangas River in Malaysia.

\section{EXPERIMENTAL}

\section{Chemicals}

Drug standards for hydrochlorothiazde (CAS:5893-5), gliclazide (CAS: 21187-98-4), diclofenac$\mathrm{Na}$ (CAS: 15307-79-6) and mefenamic acid (CAS: 61-68-7) were obtained from Sigma Aldrich (USA). Deionised water (DIW) used was obtained from EASYpure RODI (USA). HPLCgrade methanol (MeOH) Merck (Germany), HPLC-grade acetonitrile (ACN) Merck (Germany), ethyl acetate J.T.Baker (USA), acetone (Merck, Germany) and formic acid (FA, Merck, Germany) were used.
The physicochemical properties of the four pharmaceutical compounds analysed are shown in Table 1.

\section{LC-TOF/MS instrument}

LC was performed on a Dionex Ultimate 3000/LC 09115047 (USA) system equipped with a vacuum degasser, a quaternary pump, an autosampler and UV-Vis diod array detector. Chromatography was performed on a Thermo Scientific C18 (250 mm x $2.1 \mathrm{~mm}$, i.d.: $5 \mu \mathrm{m})$ column. The injection volume was $20 \mu \mathrm{L}$. All compounds were analysed in negative ion (NI) mode and eluted off the column with a mobile phase consisting of $(A) 0.1 \%$ FA in DIW and (B) $40 \% \mathrm{ACN}$ in $\mathrm{MeOH}$ at $0.3 \mathrm{ml} / \mathrm{min}$. The elution started at $5 \% \mathrm{~B}$ and was then linearly increased to $95 \%$ B over 5 min and then kept isocratic for 5 min. Next, the elution was returned to its starting conditions over $10.1 \mathrm{~min}$ and allowed to equilibrate for $5 \mathrm{~min}$ prior to the next run. The mass spectrometry was performed on a TOF instrument (Bruker/ Germany). The results were obtained with the following settings: MS capillary voltage, 3500; collision energy for all analytes, 2 - $30 \mathrm{eV}$; drying - gas flow rate, 8 L/min; drying gas temperature, $190{ }^{0} \mathrm{C}$; and nebuliser pressure, 4 bar. Lock mass was performed in the mass range $\mathrm{m} / \mathrm{z} 100-500$ using mixture of formic acid and sodium hydroxide.

\section{Stock and standard solutions}

Individual stock standard solutions $(1 \mathrm{mg} / \mathrm{ml})$ were prepared in HPLC-grade methanol and stored at $-18^{0} \mathrm{C}$ to minimise the degradation of the standard. A mixture of all pharmaceutical standards was prepared by appropriate dilution of the individual stock solutions. Further dilutions of this mixture were prepared in DIW before each analytical run and were used as the working standard solutions.

\section{Calibration}

Mixed standard solutions containing hydrochlorothiazide (5 - $500 \mathrm{ng} / \mathrm{mL}$ ), gliclazide (5 - $500 \mathrm{ng} / \mathrm{mL})$, diclofenac $-\mathrm{Na}(5-500 \mathrm{ng} / \mathrm{mL}$ ) and mefenamic acid (5 - $500 \mathrm{ng} / \mathrm{mL}$ ) were prepared in methanol and further dilution with DIW. Three replications of $20 \mu \mathrm{L}$ injections were made for each standard solution to check the repeatability of the detector response (peak area) at each concentration level. The peak area of each drug was plotted against the concentration to obtain a calibration graph. Four points of each compound were subjected to regression analysis to calculate the calibration equation and determination coefficients $\left(R^{2}\right)$. 
Table 1: Physicochemical properties and molecular structure of pharmaceutical compounds

\begin{tabular}{|c|c|c|c|c|c|}
\hline $\begin{array}{l}\text { Compound } \\
\text { (Therapeutic class) }\end{array}$ & $\begin{array}{l}\text { Molecular } \\
\text { structure }\end{array}$ & $\begin{array}{l}\text { Molecular } \\
\text { weight }\end{array}$ & pKa & $\log k_{0} w$ & DDD (mg) \\
\hline Hydrochlorothiazide & & 297.739 & $7.9^{(1)}$ & -0.07 & $25(\mathrm{O})$ \\
\hline Gliclazide & & 323.412 & NA & 2.12 & $60(0)$ \\
\hline Diclofenac-Na & & 318.149 & $4.2^{(\mathrm{RV})}$ & 0.70 & $\begin{array}{l}100 \\
(\mathrm{O}, \mathrm{P}, \mathrm{R})\end{array}$ \\
\hline Mefenamic acid & & 241.2851 & $4.2^{(1)}$ & 5.12 & $1000(0)$ \\
\hline
\end{tabular}

$O=$ oral; $P=$ parenteral; $R=$ rectal .

\section{Sample preparation}

Tangkas river is one of the major rivers in Kajang, Malaysia. Samples of river water were collected in January 2013 and there was no rain for at least two days prior to sample collection.

All samples were collected in $1.0 \mathrm{~L}$ amber glass bottles pre-rinsed with ultra-pure water and $\mathrm{MeOH}$. Sampling bottles were stored at $4{ }^{\circ} \mathrm{C}$, until SPE experiments, to minimize degradation of pollutants.

\section{Solid phase extraction (SPE)}

In the laboratory, $1.0 \mathrm{~L}$ aliquot of samples were filtered through $0.7 \mu \mathrm{m}$, GF/F filter paper from Whatman (UK) to remove particulate matters.

The solid phase extraction (SPE) procedure was performed using Oasis HLB (3 cc) SPE cartridges (Waters, MA,USA).The SPE method was optimised using $100 \mathrm{~mL}$ of filtered river water fortified with $1 \mu \mathrm{g} / \mathrm{L}$ of pharmaceuticals to select the best elution solvent.
The recovery of the target analytes from samples was tested with the $\mathrm{pH}$ adjusted by 1 $\mathrm{mol} / \mathrm{L} \mathrm{HCl}$ to $\mathrm{pH} 2.5$ and without $\mathrm{pH}$ adjustment (neutral $\mathrm{pH}$ ). For the preconcentration step, a GAST vacuum system (DOA-P504-BN, USA) was used. The cartridges were preconditioned with $5 \mathrm{~mL}$ of methanol and $5 \mathrm{~mL}$ of ultra-pure water at a flow rate $9-10 \mathrm{~mL} / \mathrm{min}$. A sample volume of $100 \mathrm{~mL}$ was percolated through the cartridges at a flow rate of $9-10 \mathrm{~mL} / \mathrm{min}$. The cartridges were allowed to dry for 10 min under vacuum to remove excess water at flow rate 14 $15 \mathrm{~mL} / \mathrm{min}$. The retained analytes were eluted with $5 \mathrm{~mL}$ of methanol.

The extract was evaporated to dryness under a gentle stream of $\mathrm{N}_{2}$ gas with the aid of a hot plate heated at $35-40{ }^{\circ} \mathrm{C}$ and re dissolved with $1 \mathrm{~mL}$ of DIW thus, obtaining a $100 \mathrm{~mL}$-fold preconcentration. Finally, $20 \mu \mathrm{L}$ of the final concentrate was injected into LC-TOF/MS instrument. The injection was repeated three times. 


\section{Statistical analysis}

The statistical analysis was achieved for collision energy, recovery and type of sorbent using SPSS software(Ver. 19), Analysis of Variance (ANOVA Duncan) at significance value is $p=$ 0.05 .

\section{RESULTS}

The mobile phase and elution program are important for achieving good separation of organic compounds. In this work, several experiments were performed using different elution programs and mobile phases to obtain the best separation and signal to noise ratio. Figure 1 presents the total ionic chromatogram (TIC) for all the pharmaceutical components.

\section{Linearity}

Hydrochlorothiazide, gliclazide, diclofenac- $\mathrm{Na}$ and mefenamic acid showed good linearity in the range $5-500 \mathrm{ng} / \mathrm{mL}$ and $\left(R^{2}\right)$ was $>0.99$.

\section{Detection limit}

The limit of detection (LOD) and limit of quantification (LOQ) were defined and determined as the minimum detectable amount of analyte with $\mathrm{S} / \mathrm{N}$ ratio of $3: 1$ and 10:1, respectively, from spiked Tangkas river and ranged from $65-136 \mathrm{ng} / \mathrm{L}$ and $215-450 \mathrm{ng} / \mathrm{L}$, respectively.

The instrumental detection limits (IDLs) were determined by direct injection of serial dilutions of the standard solution as a mixture down to a concentration of $1.6 \mathrm{ng} / \mathrm{mL}$. The IDL is defined as an $\mathrm{S} / \mathrm{N}$ ratio of $3: 1$, and the linearity is presented in Table 2.

\section{SPE method}

Extraction recovery of the analytes was determined using deionised water (DIW) and Tangkas River spiked with the analytes at a concentration of $1 \mathrm{ng} / \mathrm{mL}$. The reproducibility of the method was determined by the repeated analysis ( $n=3)$ of a spiked river water at concentrations levels of $1 \mathrm{ng} / \mathrm{mL}$ and expressed as the relative standard deviation (RSD) of replicate measurements. Three elution solvents were optimized to select the best solvent for extraction the pharmaceuticals from water as shown in Table 3.

\section{Optimisation of collision energy}

In order to develop an effective method for the analysis of the pharmaceuticals in aquatic environment, preliminary tests were performed in order to select adequate and optimum conditions. Collision energy was optimized at different values starting from 2 to $30 \mathrm{eV}$ to find the optimum value for all analytes (Figure 2).

\section{Influence of pH adjustment on recovery}

The effect of sample acidification was evaluated. Table 4, shows the recovery obtained for $100 \mathrm{~mL}$ river water fortified with $1 \mathrm{ng} / \mathrm{mL}$ of pharmaceutical standards with and without $\mathrm{pH}$ adjustment using a 3 cc Oasis HLB cartridge.

\section{Effect of different cartridges}

Different cartridges were used to study the recovery of target compounds, including $\mathrm{MCX}$ (mixed mode cationic exchange), SupelcleanTM ENVI-Chrom P (highly crosslinked, neutral, specially cleaned styrene divinylbenzene copolymer resin used to retain hydrophobic compounds with some hydrophilic functionality under reversed phase conditions), Oasis HLB cartridges (universal polymeric reversed-phase sorbent developed for the extraction of a wide range of acidic, basic, and neutral compounds) and SupelcleanTM LC-SAX (quaternary amine, $\mathrm{Cl}^{-}$counter-ion, ion exchanger and reversephase sorbent cartridge). Thus, multiple interior structures were used among the different cartridges (Table 4).

\section{Detection of pharmaceuticals in real sample}

Several experiments were performed to demonstrate the applicability of the developed method. The developed method was used to analyse surface water (Tangkas River water) in order to identify four pharmaceutically active compounds in the river.

\section{DISCUSSION}

The performance of the different elution solvents was evaluated, including $5 \mathrm{~mL}$ of $\mathrm{MeOH}$ (Eluent 1), $5 \mathrm{~mL}$ of ethyl acetate (Eluent 2) and a mixture of $3 \mathrm{~mL}$ of $70: 30$ acetone-MeOH and $2 \mathrm{~mL}$ of 30:70 acetone-MeOH (Eluent 3). All pharmaceuticals in this study have different polarities in terms of $\log \mathrm{K}_{\text {ow }}$ : hydrochlorothiazide $(-0.07)$, gliclazide (2.12), diclofenac- $\mathrm{Na}(0.7)$ and mefenamic acid (5.12).

Based on the results obtained, hydrochlorothiazide is the most polar compound while mefenamic acid is the least polar. 
Table 2: Instrumental performance and validation data

\begin{tabular}{lllcc}
\hline Compound & \multicolumn{3}{c}{ Linearity } & Linear equation \\
\cline { 2 - 4 } & Range $(\mathbf{n g} / \mathbf{m L})$ & $\mathbf{R}^{\mathbf{2}}$ & $\begin{array}{c}\text { IDL } \\
\text { (ng/mL) }\end{array}$ \\
\hline Hydrochlorothiazide & $5-500$ & $\mathrm{Y}=370.081 \mathrm{X}+9300.37$ & 0.993 & 3.7 \\
Gliclazide & $5-500$ & $\mathrm{Y}=338.468 \mathrm{X}+1287.28$ & 0.997 & 3.8 \\
Diclofenac-Na & $5-500$ & $\mathrm{Y}=297.695 \mathrm{X}+58.462$ & 0.995 & 6.3 \\
Mefenamic acid & $5-500$ & $\mathrm{Y}=616.176 \mathrm{X}+10950.2$ & 0.994 & 1.6 \\
\hline
\end{tabular}

Table 3: Optimisation of three eluents for extraction of pharmaceuticals from DIW spiked with $1 \mathrm{ng} / \mathrm{Ml}$

\begin{tabular}{llll}
\hline Compound & \multicolumn{3}{l}{ Recovery (RSD\%, $\mathrm{n=3}$ ) } \\
\cline { 2 - 4 } & $\begin{array}{l}\text { Methanol } \\
\text { (Eluent 1) }\end{array}$ & $\begin{array}{c}\text { Ethyl Acetate } \\
\text { (Eluent 2) }\end{array}$ & $\begin{array}{c}\text { Acetone } \\
\text { (Eluent 3) }\end{array}$ \\
\hline Hydrochlorothiazide & $90.7(0.38)$ & $75.9(6)$ & $85.6(1.2)$ \\
Gliclazide & $84.2(0.5)$ & $97(6)$ & $62(2.8)$ \\
Diclofenac-Na & $111.8(1.2)$ & $116.5(4.6)$ & $118.6(5.1)$ \\
Mefenamic acid & $97.9(1.3)$ & $111.7(0.2)$ & $86.4(4.8)$ \\
\hline
\end{tabular}

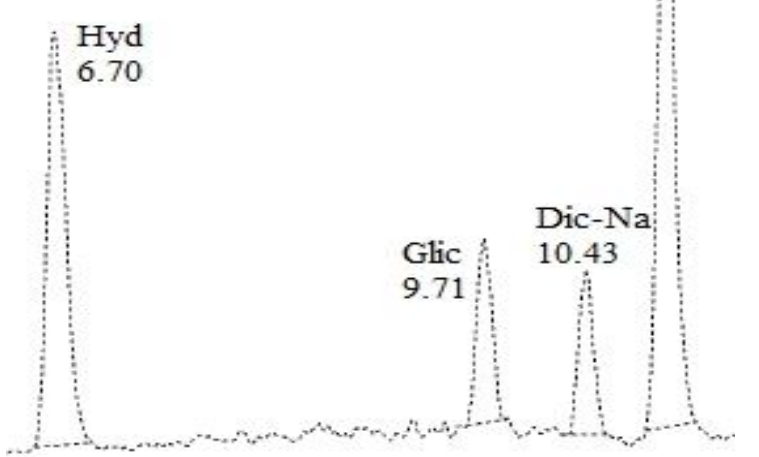

Figure 1: Total ionic chromatogram (TIC) for hydrochlorothiazide (Hyd); gliclazide (Glic); diclofenac sodium (Dic-Na); and mefenamic acid (Mef)

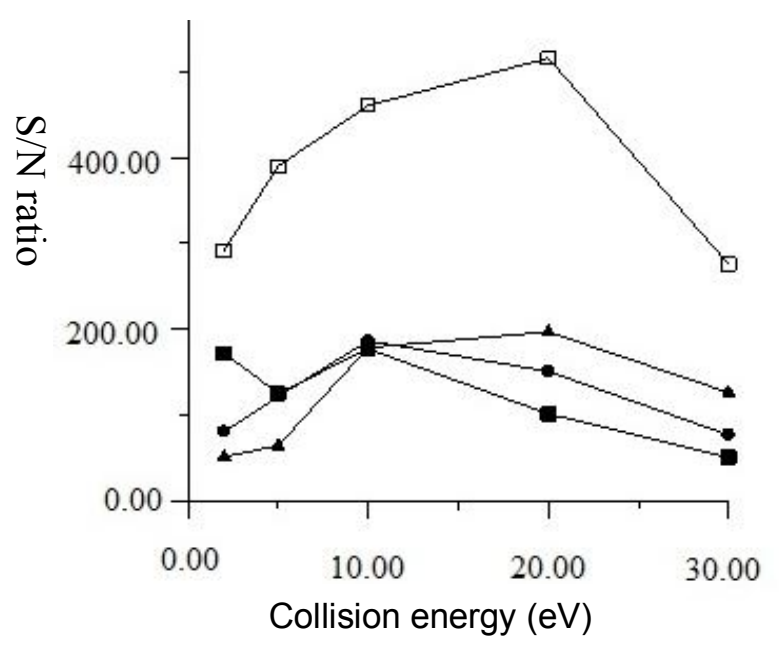

Figure 2: Optimization collision energy using LCESI-QTOF/MS of mefenamic acid (口), hydrochlorothiazide $(\boldsymbol{\Delta}), \quad$ gliclazide $(\bullet)$ and diclofenac- $\mathrm{Na}(\mathbf{\square})$.

Table 4: Effect of $\mathrm{pH}$ and cartridge on recovery of extraction from real sample spiked with $1 \mathrm{ng} / \mathrm{mL}$ of standards

\begin{tabular}{lcccccc}
\hline Compound & \multicolumn{2}{c}{ Recovery (\%) } & & \multicolumn{3}{c}{ Recovery \% } \\
\cline { 2 - 3 } \cline { 5 - 7 } & \multicolumn{2}{c}{$\begin{array}{c}\text { Influence of pH } \\
\text { (Oasis HLB) }\end{array}$} & & & \multicolumn{3}{c}{ Influence of cartridge } \\
\cline { 2 - 3 } & Natural, pH 6.8 & pH 2.5 & & SAX & ENV & MCX \\
\hline Hydrochlorothiazide & 86.9 & 80.4 & & ND & 59.3 & 62.5 \\
Gliclazide & 51.2 & 79.3 & & 21 & 45.2 & 15 \\
Diclofenac-Na & 111.2 & 39 & & 56.2 & 91 & 55.8 \\
Mefenamic acid & 45 & 23.5 & & 28.2 & 49.3 & 42.7 \\
\hline
\end{tabular}




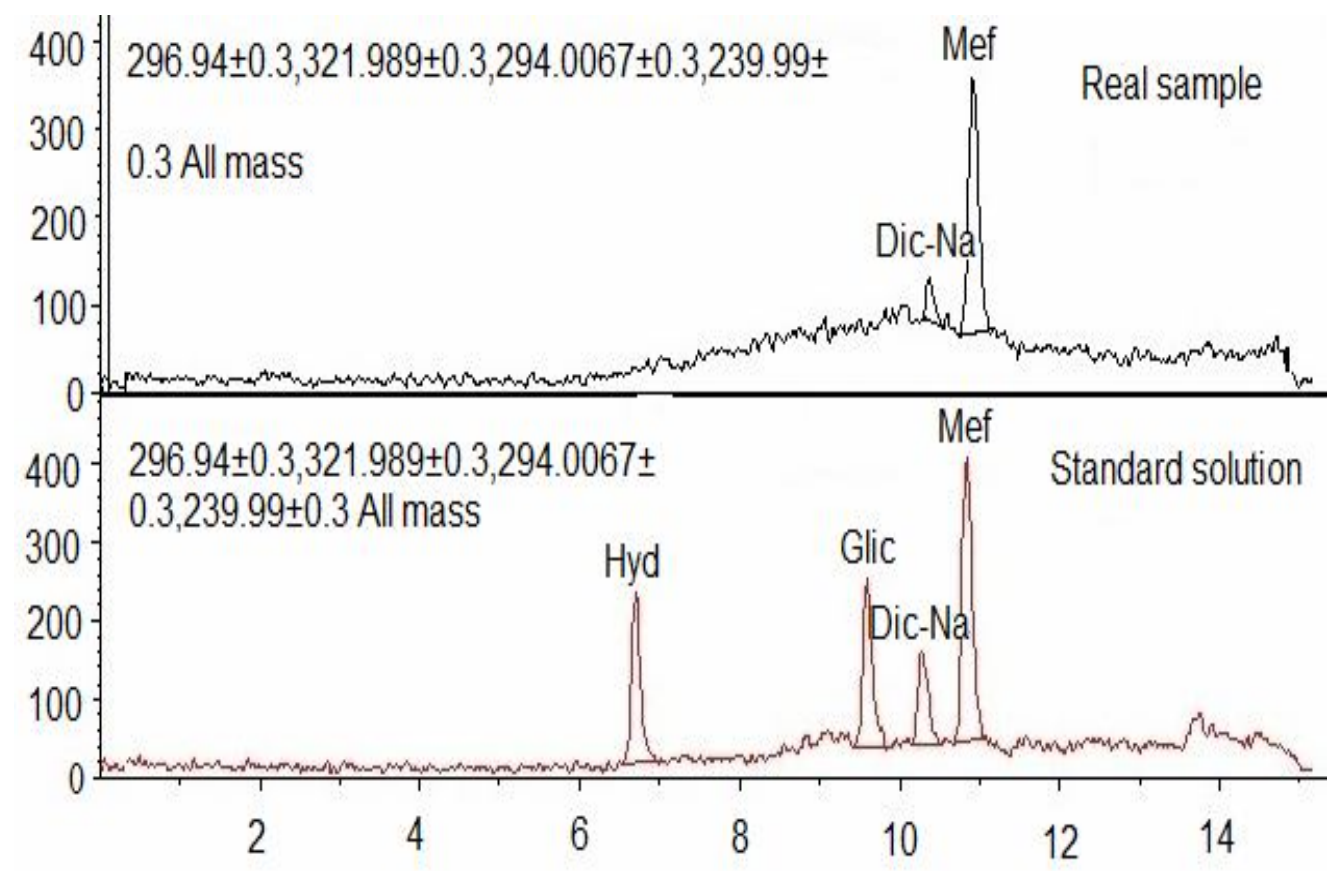

Figure 3: IIC ot pharmaceutıcals in real samples and standard solution, respectively.
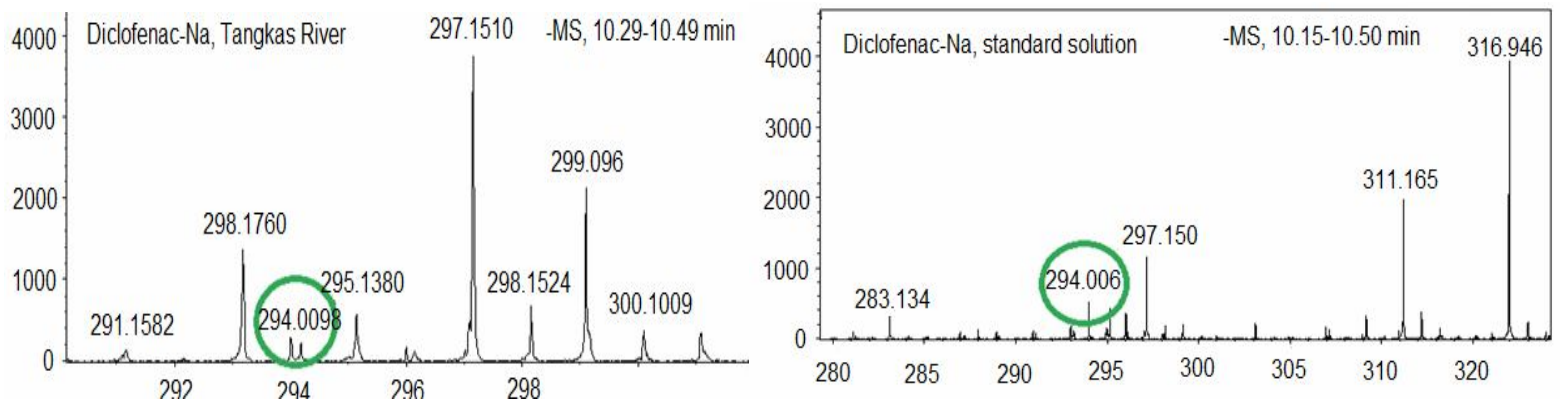

Figure 4: Mass spectra $(\mathrm{m} / \mathrm{z})$ for diclofenac-Na in real sample and standard solution, respectively
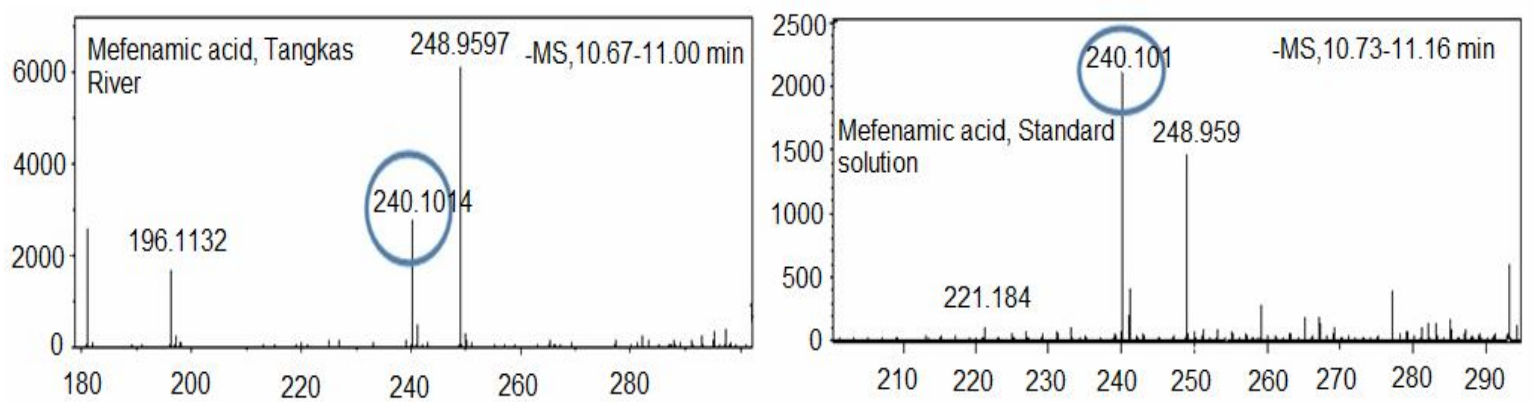

Figure 5: Mass spectra $(\mathrm{m} / \mathrm{z})$ for mefenamic acid in real sample and standard solution, respectively

Hydrochlorothiazide exhibited the lowest extraction recovery with ethyl acetate but the highest with methanol. In the case of mefenamic acid, the highest recovery was found with ethyl acetate rather than Eluent 3 or Eluent 1 . These finding may be attributed to the polarity of the compounds versus the polarity strength of the elution solvents. Based on this result, Eluent 1 was selected as a good compromise, since it extracted all the pharmaceuticals with recovery ranging from $84.2-111.8$ for $100 \mathrm{~mL}$ of distilled water fortified with $1 \mathrm{ng} / \mathrm{mL}$ of pharmaceutical.

Collision energy plays an important role in improving the $\mathrm{S} / \mathrm{N}$ ratio of compounds. The results indicate that at $10 \mathrm{eV}, \mathrm{S} / \mathrm{N}$ ratio increased 
for all analytes. However, hydrochlorothiazide and mefenamic acid showed better response at $20 \mathrm{eV}$. There was no significant difference in S/N ratio between 10 and $20 \mathrm{eV}$ for both hydrochlorothiazide and mefenamic acid. Hence, $10 \mathrm{eV}$ was selected as the optimum value as it is a good compromise for obtaining the best response for all analytes.

All the compounds yielded higher recoveries without acidification except gliclazide, in which there was higher recovery with acidification. This finding may be attributed to the protonation of $(\mathrm{N}$ -

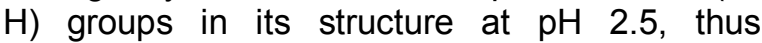
gliclazide retained strongly on HLB sorbent. Based on the results obtained at natural $\mathrm{pH}(6.8)$, our findings agree with previous results reported by Gros [19].

Different cartridges were used to select the base based on recovery values for the compounds. Oasis HLB exhibited better recovery for the compounds than the other cartridges used in this study. LC-SAX cartridge was only effective for gliclazide, diclofenac-Na and mefenamic acid. Hydrochlorothiazide was not extracted using LCSAX cartridges. Thus, this cartridge is recommended for the extraction of more hydrophobic compounds. Our results are in line with a previous study [19].

Out of the 4 target compounds (shown in Figure 3 ) only 2 compounds were detected in the river water sample (diclofenac-Na and mefenamic acid). The other target compounds may be absent or present at concentrations below the detection limits. The presence of diclofenac-Na and mefenamic acid has been reported in United Kingdom rivers but at levels that did not exceed $160 \mathrm{ng} / \mathrm{L}$ [5]. The confirmation of the detection of diclofenac-Na and mefenamic acid in the surface water was performed by comparison to the mass spectra and retention times of the standards for each compound with error $<2 \%$ and $5 \mathrm{ppm}$, respectively (Figures 4 and 5).

\section{CONCLUSION}

The developed SPE-LC-TOF/MS method was precise and accurate, allowing extraction of hydrochlorothiazide, gliclazide, diclofenac-Na and mefenamic acid from water samples. The recovery obtained for all target compounds using Oasis HLB cartridge was good relative to results from previous studies. The developed method was successfully applied for the detection of two pharmaceutical residues, diclofenac-Na and mefenamic acid, in surface water (Tangkas River, Kajang, Malaysia).

\section{ACKNOWLEDGMENT}

The authors thank Mr. Alefee, LC-TOF/MS, for providing the facilities to carry out this work, and also ALIR staff for providing ultra-pure water and facilities for sampling.

This work was financially supported by UKMDLP-2012-024, UKM-ST-06-FRGS0093-2010 and UKM-AP-2011-21.

\section{REFERENCES}

1. Ferrer I, Thurman EM. Analysis of 100 pharmaceuticals and their degradates in water samples by liquid chromatography/ quadrupole time-of-flight mass spectrometry. J Chromatogr A 2012; 1259: 148157.

2. Ternes $T$, Bonerz M, Schmidt T. Determination of neutral pharmaceuticals in wastewater and rivers by liquid chromatography-electrospray tandem mass spectrometry. J Chromatogr A 2001; 938: 175-185.

3. Al-Odainy AN, Zakaria PM, Yaziz IM, Surif S. Multi-residue analytical method for human pharmaceuticals and synthetic hormones in river water and sewage effluents by solid-phase extraction and liquid chromatography-tandem mass spectrometry. J Chromatogr A 2010; 1217: 6791-6806.

4. Yu Z, Peldszus S, Huck PM. Optimization gas chromatographic - mass spectrometric analysis of selected pharmaceuticals and endocrinedisrupting substances in water using factorial experimental design. J Chromatogr A 2007; 1148: 65-77.

5. Ashton D, Hilton M, Thomas K.V. Investigating the environmental transport of human pharmaceuticals to streams in the United Kingdom. Sci Total Environ. 2004; 333: 167-184.

6. Kasprzyk-Hordern B, Dinsdale RM, Guwy AJ. The effect of signal suppression and mobile phase composition on the simultaneous analysis of multiple classes of acidic / neutral pharmaceuticals and personal care products in surface water by solid-phase extraction and ultra performance liquid chromatographynegative electrospray tandem mass spectrometry. Talanta 2008; 74: 1299-1312.

7. Loos R, Wollgast J, Huber T, Hanke G. Polar herbicides, pharmaceutical products, perfluorooctane sulfonate(PFOS), perfluorooctanoate (PFOA), and nonylphenol and its carboxylates and ethoxylates in surface and tap waters around Lake Maggiore in Northern Italy. Anal Bioanal Chem. 2007; 387: 1469-1478.

8. Daneshvar A, Svanfelt J, Kronberg L, Weyhenmeyer GA. Winter accumulation of acidic pharmaceuticals in a Swedish river. Environ Sci Pollut Res. 2010; 17: 908-916.

9. Vulliet E, Cren-Olivé C. Screening of pharmaceuticals and hormones at the regional scale, in surface and groundwaters intended to human consumption. Environ Pollut. 2011; 159: 2929-2934.

10. Stumpf $M$, Ternes T. A, Wilken R, Rodrigues SV, Baumann W. Polar drug residues in sewage and natural waters in the state of Rio de Janeiro, Brazil. Sci Total Environ. 1999; 225: 135-141.

11. Umapathi P, Ayyappan J, Quine SD. Qauantitative determination of metformin hydrochloride in Tablet Formulation Containing Croscarmellose Sodium as Disintegrant by HPLC and UV Spectrophotometry. Trop J Pharm Res. 2012; 11: 107-116.

12. Brijesh S, Patel DK, Ghosh SK. Development of Reverse-Phase HPLC Method for Simultaneous 
Analysis of Metoprolol Succinate and Hydrochlorothiazide in a Tablet Formulation. Trop J Pharm Res. 2009; 8: 539-543.

13. Verenitch SS, Lowe CJ, Mazumder A. Determination of acidic drugs and caffeine in municipal wastewaters and receiving waters by gas chromatography-ion trap tandem mass spectrometry. J Chromatogr A 2006; 116: 193-203.

14. Langel K, Gunnar T, Ariniemi K, Rajamäki O, Lillsunde P. $A$ validated method for the detection and quantification of 50 drugs of abuse and medicinal drugs in oral fluid by gas chromatography-mass spectrometry. J Chromatogr B 2011; 879: 859-870.

15. Ahrer W, Scherwenk E, Buchberger W. Determination of drug residues in water by the combination of liquid chromatography or capillary electrophoresis with electrospray mass spectrometry. J Chromatogr A 2001; 910: 69-78.

16. Al-Qaim FF, Abdullah Md. P, Othman MR. Analysis of different therapeutic classes using liquid chromatography -mass spectrometry in aquatic environment: A review. Int J Pharm Pharm Sci. 2012; 4: 3-11.

17. Carpinteiro J, Quintana JB, Rodriguez I, Carro AM, Lorenzo RA, Cela R. Application of solid -phase microextraction followed by on-fiber silylation for the determination of estrogens in water samples by gas chromatography-tandem mass spectrometry. $J$ Chromatogr A 2004; 10569: 179-185.

18. Payana MR, Lopeza M. AB, Fernandez-Torresa $R$, Mochona MC, Arizab JLG. Application of hollow fiber-based liquid-phase microextraction (HFLPME) for the determination of acidic pharmaceuticals in wastewaters. Talanta 2010; 82: 854-858.

19. Gros M, Petrovic M, Barcelo D. Development of a multiresidue analytical methodology based on liquid chromatography-tandem mass spectrometry (LC$M S / M S$ ) for screening and trace level determination of pharmaceuticals in surface and wastewaters. Talanta 2006; 70: 678-690. 